\title{
REDES SOCIAIS, COMPANHIAS TECNOLÓGICAS E DEMOCRACIA
}

\section{Francisco Balaguer Callejón}

Catedrático de Direito Constitucional na Universidade de Granada, Espanha.

Traduzido do castelhano por Hugo César Araújo de Gusmão.

\begin{abstract}
Resumo: São muitos os âmbitos nos quais as redes sociais têm gerado disfunções do ponto de vista constitucional e democrático. Desde os direitos fundamentais até os processos eleitorais, passando pela própria configuração da ordem constitucional, num contexto no qual as condições do espaço e do tempo foram transformadas em razão da globalização e do desenvolvimento tecnológico. Novas pautas culturais e novos paradigmas estão em surgimento e sua incidência sobre o constitucionalismo é muito ampla. Algumas das mudanças trazidas pelas redes sociais podem ser estruturais e manterse-ão previsivelmente no futuro. Outras, no entanto, podem se considerar diretamente vinculadas aos interesses das companhias tecnológicas e deveriam ser objeto de revisão para evitar que levem a uma involução democrática. A intervenção dos poderes públicos, estatais e supranacionais, é cada vez mais necessária para controlar tais companhias.
\end{abstract}

Palavras-chave: Redes sociais. Companhias tecnológicas. Democracia. Constituição. Direitos fundamentais.

Sumário: Introdução - 10 contexto da globalização - 2 Transformação de pautas culturais e mudança de paradigma - $\mathbf{3}$ Constituição, democracia e redes sociais - $\mathbf{4}$ As companhias de internet e redes. Aspectos problemáticos - $\mathbf{5}$ Os processos comunicativos e a construção do espaço público 6 Os processos eleitorais - 7 Possíveis áreas de atuação - Conclusões - Referências

\section{Introdução}

As redes sociais haviam despertado grande expectativa em relação ao impulso dos processos democráticos ante regimes ditatoriais e em relação às possibilidades de melhorar a qualidade democrática dos sistemas constitucionais. No entanto, a forma como estão sendo gerenciadas pelas companhias tecnológicas pôs em xeque seu funcionamento, do ponto de vista da sua compatibilidade com os direitos constitucionais, sua incidência negativa nos processos democráticos, especialmente nos eleitorais, e o respeito às regras da competição por parte destas companhias, entre outros âmbitos. No título deste trabalho já se incorpora uma referência às companhias tecnológicas como um fator que deve ser situado 
atualmente na relação entre as redes sociais e a democracia para compreender a natureza dos problemas que enfrentamos. As inércias do desenvolvimento tecnológico, que é no século XXI um instrumento de legitimação muito potente, levam às vezes a pensar, de forma inconsciente, que as redes sociais são pouco menos que um fenômeno natural, desligado do mercado e sem relação com o interesse, muitas vezes espúrio, das companhias tecnológicas que as gerenciam. Tais companhias estão construindo um novo mundo e o fazem em função de suas expectativas de benefício econômico, sem que pareça lhes importar a lesão a direitos gerada por esta orientação no sentido da rentabilidade econômica e a incidência negativa que sua atividade manifesta sobre os processos democráticos e os sistemas constitucionais.

Ante as companhias tecnológicas, os governos dos Estados e especialmente a Administração norte-americana, que é a principal responsável pelo seu controle, estão reagindo muito lentamente e, quando o fazem, é sem intervenção alguma em relação aos problemas constitucionais gerados ou através de intervenções mínimas que não servem para corrigir os problemas. Paradoxalmente, é a União Europeia juntamente com alguns Estados europeus que está fazendo frente em maior medida aos desmandos destas companhias. Um paradoxo aparente se levarmos em consideração que a permissividade dos reguladores norte-americanos pode ter como contrapartida um interesse estratégico na acumulação de dados em nível mundial por parte destes e sua utilização pelas agências de segurança norte-americanas. Algo que já foi possível contrastar em relação à Cambridge Analytica, que, ao tempo em que intervinha de maneira fraudulenta em processos eleitorais no Reino Unido, mantinha também relações em âmbitos como a defesa ou serviços de inteligência e de segurança. ${ }^{1}$

Para entender o alcance dos problemas podemos fazer uma comparação com a forma como se desenvolviam (e continuam se desenvolvendo em parte) os processos comunicativos, tanto privados como públicos, antes do surgimento das redes sociais e das grandes plataformas de internet. As comunicações privadas estavam, e continuam estando, sujeitas a uma proteção constitucional: a correspondência ou as conversações telefônicas não podem ser interceptadas senão com uma autorização judicial. Os meios de comunicação são plurais e devem dar uma informação objetiva, diferenciável das diversas opiniões difundidas através deles. A publicidade está sujeita a certas regras e deve ser oferecida de maneira diferenciada nos meios sem que a publicidade subliminar seja admissível.

1 Cfr. INGLATERRA. House of Commons. Digital, Culture, Media and Sport Committee, DCMS. Disinformation and 'fake news': Final Report. Londres: House of Commons, 2019. p. 78. Disponivel em: https:// publications.parliament.uk/pa/cm201719/cmselect/cmcumeds/1791/1791.pdf. Acesso em: 29 maio 2020. 
Levando em consideração as condições anteriores, imaginemos agora que alguém tem a possibilidade de conhecer nossa correspondência, que pode ouvir tudo que falamos a qualquer momento e até mesmo saber o que estamos lendo no jornal a cada dia, o tempo que dedicamos a cada notícia, assim como o tipo de notícias ou de artigos que nos interessa ou nos desagrada e a reação que nos provoca sua leitura. Imaginemos também que, com todos estes dados, alguém tem a capacidade de processá-los, de definir por meio de algoritmos quais são nossos gostos e de oferecer-nos justamente aquelas coisas que mais nos agradariam comprar, através de uma propaganda personalizada. Demos um passo adiante e pensemos que tais dados são utilizados para conhecer não somente nossas preferências, mas também nossas fobias e nossos medos e que com eles se elabora um perfil psicológico individualizado que possibilita o envio de propaganda política subliminar orientada a mudar o sentido de nosso voto em determinada eleição ou a obstruir nossa participação no processo eleitoral.

Pois bem, isto é exatamente o que aconteceu em alguns dos últimos processos eleitorais celebrados no mundo, começando pelo referendo sobre o Brexit e seguindo pelas eleições presidenciais nos Estados Unidos. Em sua vertente mais grave, o que fizeram algumas plataformas que gerenciam redes sociais não foi tentar convencer abertamente os eleitores de que mudassem seu voto, mas utilizar perfis psicológicos previamente gerados através de algoritmos para produzir uma rejeição contra uma candidatura concreta. Por exemplo, se de todos os dados processados se determina uma fobia particular em relação a cachorros, a determinada pessoa são enviadas fotos de um candidato ou uma candidata acariciando tais animais, para gerar instintivamente e de maneira inconsciente uma sensação de rechaço. Se esta propaganda subliminar se combina com outras operações similares, através de fake news e mensagens desalentadoras sobre esta candidatura, talvez não se consiga uma mudança de voto, porém sim é mais possível que se obtenha como resultado a abstenção do destinatário. Quando isto é feito massivamente e de forma personalizada sobre milhares ou milhões de pessoas, o desequilíbrio do processo eleitoral é mais que provável. No caso das eleições presidenciais norte-americanas resta comprovado que foi assim nos estados decisivos sobre conjuntos muito amplos de eleitores e que foi possivel mudar o sentido da eleição nestes estados.

Naturalmente, se realizamos comparações históricas sempre podemos dizer que nos sistemas ditatoriais do século XX, por exemplo, já houve utilização de meios tecnológicos para difundir propaganda massiva, manipular a opinião pública, impor falsas narrativas e fazer com que as pessoas acreditassem em notícias falsificadas. Muitos destes fenômenos são, com diversas variantes derivadas da época concreta em que se produzem, tão antigos como a história da Humanidade. 
A novidade, na atividade de algumas companhias que gerenciam redes sociais, é que já não se trata de propaganda massiva enviada com caráter geral a um público mais ou menos amplo ou com caráter setorial a um conjunto concreto de pessoas acerca das quais se conhece basicamente suas preferências políticas ou eventualmente dados que são públicos. Pelo contrário, agora nos encontramos com propaganda política individualizada enviada a cada pessoa em função dos perfis psicológicos elaborados com algoritmos mediante o processamento de dados privados, que não deveriam ser conhecidos ou utilizados por tais plataformas. Se a isto unimos o fato de que esta propaganda pode chegar a ser subliminar e mudar nossa intenção de voto sem que possamos nos dar conta da manipulação que estamos experimentando, teremos já uma ideia da gravidade do que pode ocorrer, e ocorreu, em alguns dos últimos processos eleitorais celebrados em diversos países.

Para compreender a natureza e o alcance dos desafios enfrentados atualmente pelo sistema democrático, seria conveniente realizar alguns detalhamentos:

1. Uma parte dos problemas não está vinculada necessariamente com as redes sociais como tais e sim com a atividade das companhias tecnológicas que as gerenciam e o modelo de negócio no qual se baseiam. Tratando-se de um modelo de negócio orientado a conseguir renda publicitária, é fundamental para elas atrair a atenção do público com a finalidade de obter maiores benefícios. ${ }^{2} \mathrm{~A}$ instabilidade política, a radicalização do espaço público e a conflitividade permanente geram muito mais dinheiro do que um clima de estabilidade e de consenso.

2. Outros problemas têm a ver com a atividade de agentes globais e nacionais diferentes das companhias tecnológicas, que utilizam as redes com propósitos similares de fomento da instabilidade, em função de outros interesses que já não são necessariamente econômicos, e sim políticos ou geoestratégicos. A questão que se propõe aqui é que esta atividade favorece os interesses econômicos das companhias que gerenciam redes. Por este motivo os controles que elas implementam, quando o fazem, são menos eficazes do que aqueles que aplicam em função de outras limitações que consideram mais necessárias para sua imagem pública, de acordo com o ideário que consideram mais generalizado entre seus usuários, por exemplo.

2 Como indicam DEB, Anamitra; DONOHUE, Stacy; GLAISYER, Tom. Is social media a threat to democracy? The Omidyar Group, 2017. Disponível em: https://www.omidyargroup.com/wp-content/uploads/2017/10/ Social-Media-and-Democracy-October-5-2017.pdf. Acesso em: 29 maio 2020. 
3. Há um terceiro tipo de problema que pode estar vinculado ao tipo de suporte comunicativo e ao desenvolvimento tecnológico, que poderia ser considerado estrutural, ao menos no atual estado de desenvolvimento das plataformas. A capacidade de intervenção pública sobre eles é mais reduzida. No entanto, é fundamental estabelecer os limites reais, porque estas companhias tendem a utilizar a tecnologia como um obstáculo permanente ante qualquer controle, afirmando habitualmente haver limitações técnicas que impedem que estes controles sejam implementados.

Por outro lado, é importante analisar também o impacto das redes sociais num contexto mais amplo que aquele dos processos eleitorais (apesar de terem sido tais processos que, justificadamente, chamaram atenção do público) já que estão suscitando novos paradigmas, não somente comunicativos mas também políticos, e uma transformação das pautas culturais em muitos âmbitos. A percepção do tempo e do espaço está mudando de maneira radical no século XXI, condicionando de forma muito relevante os processos políticos e constitucionais. Algumas destas mudanças certamente não são reversíveis. A sociedade atual está sujeita a estímulos que são percebidos de forma cada vez mais urgente e volátil ao mesmo tempo. Já resta pouco da ideia de programação para o futuro própria de nossas constituições e de nossos processos constituintes. ${ }^{3}$ Os problemas são de hoje (talvez inclusive da manhã de hoje, nem sequer da tarde) e a percepção generalizada é de que têm que ser resolvidos imediatamente. Do mesmo modo, a fragmentação e a radicalização do espaço público dificultam a possibilidade de articular consensos constitucionais e democráticos. A falsificação das notícias faz parte deste cenário. Um cenário no qual os meios de comunicação tradicionais se veem cada vez mais debilitados pela tendência das grandes plataformas de internet a monopolizar o mercado publicitário. ${ }^{4}$

Delimitar em que medida a ativação de mecanismos constitucionais e democráticos de controle podem contribuir para reverter as tendências mais disfuncionais que as companhias tecnológicas de internet e redes estão produzindo é fundamental para afrontar tais processos. Não se pode afirmar, em absoluto, que as redes sociais e as plataformas são neutras e que se limitam a refletir

3 Cfr. BALAGUER CALLEJÓN, Francisco. Las dos grandes crisis del constitucionalismo frente a la globalización en el siglo XXI. Nomos, Le attualità nel diritto, Roma, 2018. Disponível em: http://www. nomos-leattualitaneldiritto.it/wp-content/uploads/2018/09/Callehon.-conv-11.05.pdf. Acesso em: 29 maio 2020. Anticipazioni Convegno: Passato, presente e futuro del costituzionalismo e dell'Europa. Existe versão italiana: "Le due grandi crisi del costituzionalismo di fronte alla globalizzazione nel XXI secolo", atualmente no prelo.

4 Cfr. PITRUZZELLA, Giuseppe. La libertà di informazione nell'era di Internet. In: PITRUZZELA, Giovanni; POLLICINO, Oreste; QUINTARELLI, Stefano. Parole e potere: libertà d'espressione, hate speech e fake news. Milão: Egea, 2017. 
tendências sociais. No mínimo, resta patente que estão potencializando justamente as tendências mais problemáticas para os direitos constitucionais, a estabilidade do sistema democrático e a limpeza dos processos eleitorais. Fazem-no, ademais, através de atividades que atingem diretamente os direitos fundamentais e para gerar maiores ganhos através de um modelo de negócio ao qual se apresenta especialmente favorável a instabilidade política. São muitos os âmbitos nos quais se podem adotar medidas de controle em nivel estatal e europeu para impedir que o sistema democrático continue se deteriorando. Desde a intervenção sobre o próprio modelo de negócio destas plataformas até a regulamentação do mercado publicitário, para impedir que terminem monopolizando-o em detrimento dos meios de comunicação tradicionais. No âmbito específico dos processos eleitorais estas medidas deveriam ter um maior alcance, ativando todos os meios necessários para impedir a manipulação eleitoral e garantir que as eleições sejam limpas e plenamente democráticas.

\section{0 contexto da globalização}

\subsection{Aceleração do tempo e ampliação do espaço público}

Há dois fenômenos que confluem para a temática que estamos abordando: por um lado, a aceleração do tempo histórico e, por outro, a ampliação do espaço público. O que está acontecendo no século XXI, no contexto da globalização, é que os termos do jogo político e constitucional estão se transformando, como consequência do desenvolvimento tecnológico. ${ }^{5}$ Surgiram novos paradigmas, especialmente nos processos comunicativos, que expressam uma transformação de pautas culturais de grande alcance. A globalização não somente acelerou o desenvolvimento tecnológico (ao ponto de que se calcula que somente os dez primeiros anos do século XXI equivalem em avanços científicos e tecnológicos a todo o século $\mathrm{XX}$ ) como mudou a relação dos seres humanos com as dimensões de espaço e tempo previamente conhecidas. A progressiva ampliação dos espaços em âmbito global produziu uma correlativa aceleração do tempo. Estamos falando, portanto, dos parâmetros essenciais nos quais se desenvolveram movimentos, atividades e instituições sociais que agora se encontram ante um contexto muito diferente daquele que Ihes viu nascer.

5 Nas palavras de D. Rousseau, "Au-delà même de la question du numérique, ce qui se joue en ce début de siècle, c'est la fin d'un monde fabriqué au xixe siècle et relookée au xxe" (ROUSSEAU, Dominique. Le numérique, nouvel objet du droit constitutionnel. Les Nouveaux Cahiers du Conseil constitutionnel, v. 57, n. 4, 2017. p. 9). 
Isso é o que ocorre com o constitucionalismo. Sua relação genética com o espaço e o tempo é muito diferente daquela gerada no contexto da globalização. No que tange ao espaço, o constitucionalismo moderno vinculou-se historicamente ao Estado. Surge historicamente como um movimento que tenta limitar e controlar o poder do Estado e adaptou-se às mudanças sociais e políticas sempre dentro do âmbito do Estado nacional. A projeção do constitucionalismo no plano supranacional está produzindo transformações importantes tanto no que se refere ao conceito de Constituição como no que tange aos próprios Estados nacionais e seus sistemas constitucionais internos. ${ }^{6}$ Porém, além destas transformações, que poderiam dar lugar no futuro a uma revitalização do constitucionalismo na esfera supranacional, o certo é que muitas das funções que a Constituição podia cumprir no seio do Estado tornaram-se, hoje, em grande parte ineficazes ante os grandes agentes globais. ${ }^{7}$ Esta ineficácia resulta particularmente evidente ante os especuladores financeiros e as companhias tecnológicas de comunicação pela internet, que atuam em âmbito global e que não encontram freio algum nas políticas ou legislações estatais.

No que tange ao tempo, o novo ritmo que marca o desenvolvimento tecnológico gerou uma percepção do tempo incompativel com alguns dos traços históricos do constitucionalismo. Pensemos, por exemplo, nos processos constituintes, com sua vocação para estabelecer normas fundamentais estáveis com capacidade de integração política e social. O caráter imediato na resposta aos problemas políticos e sociais, que é uma característica específica do espaço público que está surgindo através das redes sociais, dificulta o pensamento nos termos em que foram tradicionalmente desenvolvidos os processos constituintes ou de reforma constitucional. É cada vez mais difícil estabelecer uma programação no tempo em termos de estabilidade, o que era uma das funções específicas das constituições. O tempo das constituições, tal como o conhecemos até agora, não é coerente com as características do espaço público configurado desde alguns anos atrás por meio das redes sociais. ${ }^{8}$

6 Cfr. BALAguer CALLEJón, Francisco. El Tratado de Lisboa en el Diván. Una reflexión sobre constitucionalidad, estatalidad y Unión Europea. Revista Española de Derecho Constitucional, Espanha, n. 83, maio/ago. 2008 e BALAGUER CALLEJÓN, Francisco. Constitución y Estado en el contexto de la integración supranacional y de la globalización. In: CARBONELL, Miguel; FIX-FIERRO, Héctor; GONZÁLEZ PÉREZ, Luis Raúl; VALADÉS, Diego (Coord.). Estado constitucional, derechos humanos, Justicia y vida universitaria. Estudios en homenaje a Jorge Carpizo. México: Unam, 2015. t. IV. v. 1. p. 197-211.

7 Nas palavras de D. Rousseau, “La nouvelle civilisation du numérique signe, en effet, la fin de l'État souverain national, la fin du contrôle de l'État sur l'économie et la société" (ROUSSEAU, Dominique. Le numérique, nouvel objet du droit constitutionnel. Les Nouveaux Cahiers du Conseil constitutionnel, v. 57, n. 4, 2017. p. 9).

8 Por mais que as redes sociais ofereçam também possibilidades de participar nos processos constituintes e nos legislativos. Cfr. sobre os primeiros, SALES, Eric. La transformation de l'écriture de la Constitution, 


\subsection{Agentes globais e o Estado}

No contexto da globalização, o Estado é cada vez mais incapaz de controlar os grandes agentes globais. Esta incapacidade pode ser vista agora com as companhias tecnológicas, porém também foi vista antes nos anos da crise econômica com as políticas econômicas que podiam resultar contrárias aos princípios ou aos direitos constitucionais. Igualmente neste caso uma nova legitimidade se alçou ante uma Constituição cada vez mais marginalizada no espaço público, porque não servia como instrumento de controle do poder nem permitia garantir os direitos incorporados ao documento constitucional. Também no plano econômico há elementos estruturais derivados do processo de globalização que geram uma tensão constante com a ordem constitucional, e cuja solução não é fácil. No entanto, também aqui havia possibilidades de suscitar políticas econômicas igualmente eficazes e mais coerentes com o contexto constitucional (que não se baseassem quase exclusivamente na redução progressiva dos gastos sociais, como as que foram impostas durante a crise em alguns países europeus) que não foram possíveis dada a imposição de uma narrativa baseada na legitimidade econômica, que acabou por deslocar a Constituição para fora do espaço público de debate e decisão.

0 mesmo pode ser dito em relação à democracia pluralista. A narrativa economicista que se impôs durante a crise desvirtuou totalmente a democracia pluralista, ao obrigar a execução de determinadas políticas públicas, fosse qual fosse o resultado dos processos eleitorais. Ao ponto de que, quando os governantes nacionais não acataram tais políticas, foram substituídos por outros através de uma pressão econômica que obrigou os parlamentos nacionais a mudar governos em alguns Estados. Pode-se falar, deste ponto de vista, de uma externalização do poder político estatal durante o período da crise, que permitiu aos especuladores financeiros globais, em última instância, determinar as políticas estatais. ${ }^{9}$

Quando a crise econômica começou a ser superada, foi possível verificar, a partir do Brexit e das eleições presidenciais norte-americanas (às quais seguiramse outros processos eleitorais igualmente afetados), algo ainda mais grave: a internalização do poder político das grandes companhias tecnológicas que gerenciam redes sociais, que intervieram nas eleições, com técnicas absolutamente

l'exemple islandais. Les Nouveaux Cahiers du Conseil constitutionnel, v. 57, n. 4, p. 45-57, 2017 ; e sobre os segundos, VIDAL-NAQUET, Ariane. La transformation de l'écriture de la loi: l'exemple de la loi sur la République numérique. Les Nouveaux Cahiers du Conseil constitutionnel, v. 57, n. 4, p. 59-68, 2017.

9 Cfr. BALAGUER CALLEJóN, Francisco. Las dos grandes crisis del constitucionalismo frente a la globalización en el siglo XXI. Nomos, Le attualità nel diritto, Roma, 2018. Disponível em: http://www. nomos-leattualitaneldiritto.it/wp-content/uploads/2018/09/Callehon.-conv-11.05.pdf. Acesso em: 29 maio 2020. 
incompatíveis com as regras democráticas, para favorecer determinados candidatos. A estas companhias unem-se agentes muito poderosos, internos e externos, que atuam nas redes, fomentando a radicalização e a fragmentação gradativa do espaço público e a orientação das tendências políticas e do voto em direção aos extremos do espectro político.

$\mathrm{Na}$ verdade, ambos os fenômenos, a externalização do poder estatal e a internalização do poder dos grandes agentes globais, se retroalimentam. Por um lado, a crise econômica favoreceu a geração de um substrato social cada vez mais radicalizado ante a globalização e mais frustrado ante a incapacidade do Estado e, portanto, do sistema representativo e democrático interno, de resolver os problemas sociais. Por outro lado, as grandes plataformas que gerenciam redes sociais promoveram esta radicalização ${ }^{10}$ utilizando todos os meios a seu alcance, não por uma orientação ideológica própria destas plataformas, e sim para incrementar seus ganhos com o atual modelo de negócio no qual desenvolvem sua atividade. Conforme já indicamos, para este modelo de negócio torna-se vital chamar a atenção do público e fomentar a polêmica e a instabilidade, o que gera um aumento de seus ganhos publicitários. ${ }^{11}$

\section{Transformação de pautas culturais e mudança de paradigma}

Algumas das tendências que o desenvolvimento tecnológico trouxe não se modificarão para uma melhor compatibilização com os ditames do constitucionalismo, pois expressam uma transformação de pautas culturais que atualmente parece imparável. Nelas a tensão entre constitucionalismo e desenvolvimento tecnológico é estrutural e tem difícil solução. Em relação a outras tendências, no entanto, é possível e desejável uma regulamentação que, partindo dos princípios e valores constitucionais, garanta os direitos fundamentais e a lisura nos processos eleitorais, ambos ameaçados atualmente pelas companhias tecnológicas. No entanto é neste ponto que a nova legitimação tecnológica se enfrenta de maneira radical com o constitucionalismo, porquanto apela de maneira permanente a razões técnicas para impedir qualquer regulamentação das

10 Como afirma Idris Fassassi: “Les réseaux ne font qu'accentuer les tendances lourdes de l'environnement dans lequel ils opèrent" (FASSASSI, Idris. Les effets des réseaux sociaux dans les campagnes électorales américaines. Les Nouveaux Cahiers du Conseil constitutionnel, v. 57, n. 4, p. 69-86, 2017. p. 86).

11 Cfr. DEB, Anamitra; DONOHUE, Stacy; GLAISYER, Tom. Is social media a threat to democracy? The Omidyar Group, 2017. Disponível em: https://www.omidyargroup.com/wp-content/uploads/2017/10/SocialMedia-and-Democracy-October-5-2017.pdf. Acesso em: 29 maio 2020. 
atividades destas plataformas. Na narrativa que estas companhias estão logrando impor, a Constituição e os direitos representam um obstáculo para o progresso por elas oferecido.

Em todo caso, é perceptível uma mudança de pautas culturais com dimensão histórica com o avanço da internet e das redes sociais. A dependência crescente da tecnologia, as transformações dos modelos comunicativos interpessoais e sociais, a fragmentação do espaço público, o efeito de bolha, a radicalização dos debates e a dificuldade para estabelecer consensos estão entre os muitos âmbitos nos quais tais mudanças são perceptíveis. No plano comunicativo e político podemos ver uma progressiva orientação do parlamento no sentido de atitudes e práticas que tendem a convertê-lo num cenário que depois se projeta sobre as redes sociais. 0 mesmo ocorre com os partidos políticos e sua crescente dependência das agendas que delimitam, para as redes sociais, as temáticas a serem debatidas e as estratégias a seguir. Os limites desta evolução não estão claramente definidos e a possibilidade de reverter algumas destas tendências tampouco é perceptível atualmente.

\section{Constituição, democracia e redes sociais 3.1 Constituição e redes sociais}

No âmbito especificamente constitucional, podemos apreciar uma transformação das condições estruturais de desenvolvimento do constitucionalismo e da própria noção de Constituição, diante da nova configuração do espaço e do tempo políticos. No que se refere a este, cabe falar de uma dificuldade para desenvolver processos constituintes ou de reforma que tem relação com o desaparecimento do consenso como fórmula de solução de conflitos, com a impossibilidade de realização de uma programação em longo prazo própria das constituições, com a indiferença em relação aos direitos constitucionais no debate público, com a debilidade dos meios de comunicação tradicionais etc.

No que tange especificamente ao espaço público nacional, que foi o âmbito no qual o constitucionalismo se desenvolveu até o momento, as mudanças introduzidas pelo desenvolvimento tecnológico, especialmente através da internet e das redes sociais, são muito relevantes. ${ }^{12} \mathrm{~A}$ fragmentação progressiva do espaço

12 Certamente, não é possível valorar tais mudanças somente por uma perspectiva negativa pois, conforme indicam Julien Bonnet e Pauline Türk, “Les technologies numériques n'étant qu'un outil, c'est la façon dont elles vont être utilisées, développées et encadrées qui déterminera, dans l'avenir, leurs effets bénéfiques ou délétères, à moyen et long terme, sur la démocratie" (BONNET, Julien; TÜRK, Pauline. Le numérique: un 
público gerada, ou, no mínimo, potencializada, pelas companhias tecnológicas que gerenciam redes sociais, dificulta a possibilidade de lograr consensos sociais amplos voltados para a ordenação global do conjunto da sociedade por meio de instrumentos constitucionais. O impacto das redes sociais sobre os direitos é outra das vertentes nas quais o desenvolvimento tecnológico pressiona a armadura constitucional nacional. ${ }^{13}$ Porém a mais relevante se manifesta hodiernamente na própria densidade democrática do Estado devido à atividade de manipulação eleitoral levada a cabo algumas companhias tecnológicas que gerenciam redes sociais em processos eleitorais recentes. ${ }^{14}$

\subsection{Processos democráticos e redes sociais}

O modelo de negócio que ampara as redes sociais, por meio das companhias que as gerenciam, e sua dependência em relação à propaganda conduziram a uma necessidade permanente de atrair a atenção do público, de fomentar o seu uso e o dos aplicativos de internet. No seu traslado ao plano da comunicação política, esta atenção permanente é alcançada no plano político gerando debate, radicalização e instabilidade política. Por outro lado, este modelo, construído para a negociação publicitária, mediante utilização massiva de dados pessoais e a configuração de perfis através de algoritmos, começou a ser utilizado posteriormente na propaganda política. Sua aplicação a este âmbito provocou novas lesões a direitos, ao utilizar tais perfis psicológicos para elaborar e difundir propaganda subliminar particularizada. Esta propaganda se encaixa num contexto de radicalização, fragmentação do espaço público, produção de bolhas, desinformação e falsificação de notícias, a fim de potencializar sua eficácia.

défi pour le droit constitutionnel. Les Nouveaux Cahiers du Conseil constitutionnel, v. 57, n. 4, p. 13-24, 2017. p. 18). Para valorar estes efeitos, caberia diferenciar também, como faz Coralie Richaud, a prática coletiva da individual nas redes sociais. Cfr. RICHAUD, Coralie. Les réseaux sociaux: nouveaux espaces de contestation et de reconstruction de la politique? Les Nouveaux Cahiers du Conseil constitutionnel, v. 57, n. 4, p. 29-44, 2017.

13 Como indica D. Rousseau, “Le discours anti-droits de l'homme est devenu le discours dominant" (ROUSSEAU, Dominique. 1948-2018: que reste-t-il de la Déclaration universelle des droits de l'homme? Libération, 6 dez. 2018. Disponível em: https://www.liberation.fr/auteur/8617-dominique-rousseau. Acesso em: 29 maio 2020).

14 Cfr. MARK, Scott. Cambridge Analytica helped 'cheat' Brexit vote and US election. Politico, 29 mar. 2018. Disponível em: https://www.politico.eu/article/cambridge-analytica-chris-wylie-brexit-trump-britaindata-protection-privacy-facebook/. Acesso em: 29 maio 2020. Cfr. igualmente, NIALL, Ferguson. Social networks are creating a global crisis of democracy. The Globe and Mail, 2018. Disponível em: https:// www.theglobeandmail.com/opinion/niall-ferguson-social-networks-and-the-global-crisis-of-democracy/ article37665172/. Acesso em: 29 maio 2020. 
As companhias de internet favoreceram até o momento as opções mais radicais e populistas nos processos eleitorais por distintos motivos. Entre eles, caberia destacar, em primeiro lugar, que a produção de instabilidade favorece mais ganhos financeiros com seu atual modelo de negócio. Em segundo lugar, que a deterioração e o potencial bloqueio da política dificultam o controle que os poderes públicos deveriam realizar sobre tais companhias e redes. Deste ponto de vista as companhias tecnológicas ganham sempre com a radicalização e a instabilidade política, tanto da perspectiva econômica como daquela de ampliação de seu poder em face da ausência de limites e de controles gerada pela instabilidade política que elas mesmas produzem.

\section{As companhias de internet e redes. Aspectos problemáticos}

\subsection{Incidência sobre os direitos fundamentais}

Afortunadamente resta cada vez mais claro que as redes sociais não são gerenciadas por meras plataformas estáticas atuando como intermediárias sem qualquer responsabilidade. Pelo contrário, trata-se de companhias e não meras plataformas, às quais se deve atribuir responsabilidade por práticas danosas que nelas se desenvolvem, quando nada fazem para evitá-las, ou inclusive as favorecem. Controlar tais companhias e seu modelo de negócio é fundamental para reverter a involução democrática e civilizatória que atualmente vivenciamos.

Um âmbito especialmente sensivel à atuação de tais companhias é o do impacto sobre os direitos fundamentais como o direito à privacidade ou à proteção de dados pessoais. $O$ enfraquecimento massivo do direito à proteção de dados pessoais por algumas destas companhias tecnológicas tem sido uma constante, e a incapacidade dos gestores públicos para melhor proteger os cidadãos também. O problema é que desta lesão massiva derivam outras muitas como consequência da utilização dos dados obtidos para finalidades muito distintas através dos algoritmos utilizados por tais companhias e que incidem sobre um espectro muito amplo de direitos fundamentais. Um aspecto especialmente problemático é a fragilização de direitos políticos como consequência da interferência das companhias que gerenciam redes sociais nos processos eleitorais. 


\subsection{Tendência ao monopólio e impacto da competição}

Um dos problemas mais graves suscitados pelas companhias tecnológicas é o da posição monopolista que ocupam em algumas das atividades por elas desenvolvidas. ${ }^{15}$ Esta posição foi alcançada sem que tenha havido qualquer reação significativa dos organismos reguladores. Conforme se indica no relatório Unlocking digital competition: "Over the last 10 years the 5 largest firms have made over 400 acquisitions globally. None has been blocked and very few have had conditions attached to approval, in the UK or elsewhere, or even been scrutinised by competition authorities". ${ }^{16}$

0 exemplo de Facebook é revelador. De acordo com o que se indica em Disinformation and 'fake news': Final Report, esta companhia concentrou de forma ilícita uma grande quantidade de dados pessoais posteriormente vendidos ou cedidos a outros aplicativos (em troca dos dados que lhe eram entregues por outras companhias). Todos os dados, aqueles reunidos por esta companhia e os das outras, centralizaram-se pelo Facebook. Uma vez centralizados, através de um aplicativo previamente comprado e projetado inicialmente para proteger os dados de internautas, o Facebook empreendeu um monitoramento da evolução de tais aplicativos. Aqueles que demonstravam um potencial de crescimento importante, e podiam representar uma competição no futuro, tiveram ofertas de compra por parte desta companhia. Os que não aceitaram as ofertas de compra ou foram considerados potenciais competidores no futuro foram desativados, negando-lhes acesso aos dados pessoais que constituíam a base de seu negócio e provocando sua ruína. ${ }^{17}$

15 Cfr. FROSINI, Tommaso Edoardo. Internet e democrazia. // diritto dell'informazione e dell'informatica, anno XXXII, fasc. 4-5, p. 657-671, 2017.

16 FURMAN, Jason et al. Unlocking digital competition. Report of the Digital Competition Expert Panel. Londres: Crown, 2019. p. 12. Disponível em: https://assets.publishing.service.gov.uk/government/ uploads/system/uploads/attachment_data/file/785547/unlocking_digital_competition_furman_review_ web.pdf. Acesso em: 29 maio 2020. “The largest digital companies have made extensive use of mergers, as their market shares have grown. Acquisitions have included buying businesses that could have become competitors to the acquiring company (for example Facebook's acquisition of Instagram), businesses that have given a platform a strong position in a related market (for example Google's acquisition of DoubleClick, the advertising technology business), and data-driven businesses in related markets which may cement the acquirer's strong position in both markets (Google/YouTube, Facebook/WhatsApp)" (FURMAN, Jason et al. Unlocking digital competition. Report of the Digital Competition Expert Panel. Londres: Crown, 2019. p. 11. Disponível em: https://assets.publishing.service.gov.uk/government/uploads/system/uploads/ attachment_data/file/785547/unlocking_digital_competition_furman_review_web.pdf. Acesso em: 29 maio 2020).

17 INGLATERRA. House of Commons. Digital, Culture, Media and Sport Committee, DCMS. Disinformation and 'fake news': Final Report. Londres: House of Commons, 2019. p. 26 et seq. Disponível em: https:// publications.parliament.uk/pa/cm201719/cmselect/cmcumeds/1791/1791.pdf. Acesso em: 29 maio 2020. 


\subsection{A pressão sobre os meios de comunicação tradicionais}

O modelo de negócio das companhias que gerenciam redes sociais está engendrando uma transformação importante no mercado publicitário com uma tendência ao monopólio, ocupando uma porcentagem cada vez maior deste mercado. Conforme indica The Cairncross Review. A sustainable future for journalism, os meios de comunicação estão reduzindo de forma significativa suas fontes tradicionais de renda: a circulação e a propaganda. ${ }^{18} \mathrm{~A}$ informação está sendo distribuída cada vez em maior medida através de redes sociais ${ }^{19} \mathrm{e}$ se evidencia um retrocesso permanente dos meios de comunicação tradicionais. ${ }^{20}$

A crescente debilidade dos meios de comunicação está provocando o seu desaparecimento e o enfraquecimento de sua função pública de formação de opinião a partir de uma informação objetiva e verídica. ${ }^{21}$ Ao mesmo tempo, os meios de comunicação estão experimentando também uma dependência crescente dos debates e da agenda política que se configuram nas redes sociais. Porém, enquanto os meios de comunicação tradicionais são abertos e transparentes, nas redes sociais intervieram grupos e agentes anônimos que condicionam os debates e alimentam aqueles que podem gerar mais conflito e instabilidade.

18 "The news publishing business is undergoing an extraordinary period of contraction in both of its main traditional sources of revenue: advertising and circulation" (THE CAIRNCROSS REVIEW. A sustainable future for journalism. 12 February 2019. p. 5. Disponível em: https://assets.publishing.service.gov. uk/government/uploads/system/uploads/attachment_data/file/779882/021919_DCMS_Cairncross_ Review_.pdf. Acesso em: 29 maio 2020).

19 “In 2018, the Reuters Institute for the Study of Journalism reported that $74 \%$ of UK adults used some online method each week to find news, and $91 \%$ of $18-24$ year olds. Most online news is available for free and much of it is carried by aggregators such as Google News or Apple News, posted on Facebook's news feed, or sent from one person to another at the tap of a finger" (THE CAIRNCROSS REVIEW. A sustainable future for journalism. 12 February 2019. p. 6. Disponível em: https://assets.publishing.service.gov. uk/government/uploads/system/uploads/attachment_data/file/779882/021919_DCMS_Cairncross_ Review_.pdf. Acesso em: 29 maio 2020).

20 "sales of both national and local printed papers have plunged: they fell by roughly half between 2007 and 2017, and are still dropping. In addition, print advertising revenues, which used to carry much of the cost of producing news, have fallen even faster, declining in a decade by $69 \%$. Small wonder so many news groups are struggling, including digital-only groups like HuffPost and Buzzfeed, as well as many local newspaper publishers. To cut costs, there have been mergers, as well as heavy cuts in staffing: the number of full-time frontline journalists in the UK industry has dropped from an estimated 23,000 in 2007, to 17,000 today, and the numbers are still swiftly declining" (THE CAIRNCROSS REVIEW. A sustainable future for journalism. 12 February 2019. p. 6. Disponível em: https://assets.publishing.service.gov.uk/government/uploads/ system/uploads/attachment_data/file/779882/021919_DCMS_Cairncross_Review_.pdf. Acesso em: 29 maio 2020).

21 Conforme indica Anna Papa, atende-se mais ao dado isolado que à sua inserção num processo complexo de formação de consciência, no qual o dado deve ser contextualizado para se converter em informação e, junto a outras informações com as quais se confronte, gerar consciência. Cfr. PAPA, Anna. // diritto ad essere informati nella tutela multilivello della libertà di espressione. No prelo. 
A mudança de pautas culturais no âmbito da informação favorece também a fragmentação e a radicalização. A informação nas redes se mostra desagregada e condicionada pelos algoritmos, de modo que não há uma visão ampla de todos os temas de atualidade como nos meios de comunicação tradicionais, senão que se chega à informação de maneira fragmentada e seletiva. ${ }^{22}$

\section{Os processos comunicativos e a construção do espaço público}

\subsection{0 substrato prévio, globalização e crise econômica}

As companhias de redes sociais atuam sobre um substrato prévio de descontentamento social gerado pela globalização e pela crise econômica. Este descontentamento tem a ver com uma crescente sensação de precariedade em amplas camadas da população e com o aumento da desigualdade entre setores minoritários que acumulam cada vez mais riqueza e o resto da sociedade.

Até o momento, estas companhias contribuíram para potencializar o descontentamento ao invés de canalizá-lo para oferecer soluções, o que é uma das funções essenciais dos sistemas constitucionais e democráticos. Os problemas sociais provocados em decorrência da globalização e que se viram incrementados como consequência da crise não têm fácil solução, porém devem ser abordados mediante o diálogo e a negociação através de processos democráticos e no seio dos Estados nacionais e nas estruturas supranacionais.

Pode-se afirmar, portanto, que as companhias que gerenciam redes sociais estão dificultando funções essenciais do ordenamento constitucional e dos processos democráticos. Não só não contribuem para que estas funções se realizem assim como as dificultam, ao incrementar a radicalização e potencializar os conflitos ao invés de oferecer vias de solução pacífica e democrática.

22 "Social feeds and search results show snippets and single articles. This creates a more disaggregated news experience than traditional news media". Eso supone que los usuarios no acceden más que a una parte de la información: "Online content is effectively 'unbundled'. The different sections of a print newspaper are brought together into one product. Online, readers can select only the articles they wish to view, without necessarily being exposed to other content. So, they may be less likely to read public interest newS" (THE CAIRNCROSS REVIEW. A sustainable future for journalism. 12 February 2019. p. 7. Disponível em: https://assets.publishing.service.gov.uk/government/uploads/system/uploads/attachment_data/ file/779882/021919_DCMS_Cairncross_Review_.pdf. Acesso em: 29 maio 2020). 


\subsection{A fragmentação e radicalização do espaço público}

A fragmentação do espaço público é um dos efeitos mais disfuncionais produzidos através das redes sociais com seu atual modelo de gestão. Afeta o próprio núcleo da democracia pluralista já que dificulta o reconhecimento dos outros, o respeito pela diversidade, a possibilidade de articular debates produtivos e a capacidade de oferecer soluções globais para o conjunto da sociedade.

A radicalização se vê favorecida pela fragmentação do espaço público e o efeito de bolha. ${ }^{23} \mathrm{~A}$ retroalimentação permanente das próprias ideias gera fundamentalismo. A radicalização impede o debate, converte o adversário político em inimigo e transforma a política numa luta para impor as próprias ideias que é incompatível com o conceito de democracia constitucional próprio das constituições normativas, para as quais não existe democracia sem Estado de Direito e sem respeito aos direitos das minorias.

A transformação da democracia na simples vontade da maioria parlamentar ou social implica uma involução histórica que nos conduz ao período entreguerras, no qual esta concepção de democracia esteve na base da implantação de regimes fascistas.

\section{Os processos eleitorais}

\subsection{Notícias falsificadas e desinformação}

A desinformação produzida através de notícias falsas não é algo novo na história. 0 que, sim, é novo é a capacidade que as redes sociais têm de converter tais notícias em tendências majoritárias em contextos democráticos, ocupando uma parte fundamental do espaço público. ${ }^{24}$

Também representa uma novidade o fato de que tais notícias se transmitam num âmbito de privacidade e inclusive de intimidade (por exemplo, através do WhatsApp), o que potencializa extraordinariamente sua eficácia porque elimina a distância ante o emissor da mensagem.

As notícias falsas estão destruindo o espaço público e alterando as condições estruturais dos processos democráticos. Favorecem o desenvolvimento

23 PARISER, Eli. The Filter Bubble. What the internet is hiding from you. Londres: Penguin Books, 2011.

24 Cfr. PITRUZZELLA, Giuseppe. La libertà di informazione nell'era di Internet. In: PITRUZZELA, Giovanni; POLLICINO, Oreste; QUINTARELLI, Stefano. Parole e potere: libertà d'espressione, hate speech e fake news. Milão: Egea, 2017. 
da fragmentação e radicalização e o acesso de movimentos populistas, pouco respeitosos com as regras democráticas, ao poder.

\subsection{Intervenção de agentes externos e de grupos organizados}

A intervenção de agentes externos e de grupos organizados no debate público e especificamente nos processos eleitorais é uma manifestação a mais do interesse interno e externo em gerar instabilidade e bloquear o sistema democrático.

Desafortunadamente, este interesse converge para o das companhias que gerenciam as redes. Por esta razão, além do benefício econômico direto que Ihe proporcionam tais grupos externos e internos (mediante a contratação de propaganda política), estas companhias inicialmente favoreceram tal intervenção.

Posteriormente aos grandes escândalos gerados a partir do referendo sobre o Brexit e das eleições presidenciais norte-americanas, estas companhias atuaram com eficácia relativa e diversa para controlar a intervenção externa, porém, em todo caso, de forma insuficiente.

\subsection{Perfis individuais e propaganda subliminar}

A criação de perfis individuais mediante a utilização massiva de dados pessoais e sua utilização específica para distribuição personalizada de propaganda subliminar é a atuação mais grave que pode ser atribuída às companhias gestoras de redes sociais, do ponto de vista de sua incidência nos processos democráticos.

Esta atividade apresenta claras características de criminalidade, porquanto implica uma infração às normas regulatórias do processo eleitoral passível de alterar o resultado de eleições.

Tais práticas podem conduzir à destruição dos processos democráticos. Diante delas, a coletividade está absolutamente vulnerável, porque ninguém está consciente de que sua opção política pode ser manipulada e alterada através de propaganda subliminar.

\section{Possíveis áreas de atuação}

Para afrontar os problemas que as companhias gestoras de redes sociais estão provocando nos processos democráticos, as medidas relativas unicamente 
aos processos eleitorais, por exemplo, são insuficientes. Faz-se mister partir de uma visão de conjunto de todos estes problemas, o que implica também discutir a questão do modelo de negócio que tais companhias adotam. Este modelo de negócio é, atualmente, incompatível com o que prometiam ser as redes sociais: um espaço de participação cidadã, de promoção de causas justas e de aprofundamento da democracia.

Algumas companhias construídas sobre um modelo de negócio baseado em atrair a atenção do público para gerar mais renda publicitária e que têm tendência ao monopólio ou ao oligopólio dificilmente poderão contribuir com novos instrumentos de participação democrática. Não se pode oferecer aquilo que não se tem. Companhias que não são democráticas nem na sua estrutura nem na sua finalidade não podem configurar mecanismos reais de democratização.

As medidas propostas a seguir são basicamente externas, porém também é possível pensar numa regulação das próprias redes sociais que possibilite a mudança de algumas das pautas que estão sendo implantadas e que são prejudiciais para a configuração do espaço público e dos processos comunicativos. Seria o caso, por exemplo, da implantação de procedimentos que retardem as respostas agora imediatas que, por sua própria natureza, tendem a pressionar e radicalizar os processos comunicativos.

\subsection{Direitos fundamentais}

As medidas que deveriam ser adotadas neste âmbito são de amplo espectro: desde a educação cidadã no âmbito digital para que possam ser controladas as lesões a direitos, até sanções de todo tipo contra os atentados mais graves que possam ser produzidos.

Particularmente, a educação digital deve contemplar desde os processos técnicos que favoreçam a compreensão de como funcionam as redes e a internet até os mecanismos jurídicos de regulação e, em particular, os direitos que correspondem aos usuários, assim como o conjunto de direitos suscetível de ser atacado e as medidas que o ordenamento jurídico oferece para garanti-los.

A proteção dos dados pessoais deve se estender aos modelos utilizados para seu tratamento. A elaboração de perfis deve ser submetida às limitações estabelecidas no ordenamento europeu. A elaboração de perfis psicológicos deve ser objeto de especial atenção para evitar que seja um instrumento de manipulação das consciências capaz de incidir negativamente nos processos democráticos. 


\subsection{Competição, publicidade e meios de comunicação}

O controle da competição para evitar que as companhias de internet consolidem posições de monopólio é fundamental. As práticas danosas seguidas até o momento não devem ser permitidas no futuro. Pelo contrário, seria conveniente seguir as propostas já sugeridas por alguns responsáveis políticos (como a Senadora Elizabeth Warren nos Estados Unidos) no sentido de romper os atuais monopólios, conforme já se fez outrora neste país com outras companhias para preservar a livre concorrência.

A regulação do mercado publicitário seria também necessária para evitar que tais companhias tecnológicas continuem aumentando sua quota de participação neste mercado, debilitando cada vez mais os meios de comunicação tradicionais.

De acordo com as recomendações do relatório Unlocking digital competition, os organismos reguladores deveriam mudar seus métodos de trabalho para afrontar adequadamente as condições do mercado digital, de forma que não se limitem a controlar os efeitos em curto prazo das possíveis fusões e compras de companhias, mas que analisem também sua previsível evolução posterior para evitar a consolidação de monopólios. ${ }^{25}$

\subsection{Processos eleitorais}

Faz-se necessária uma nova regulamentação eleitoral que leve em consideração o contexto tecnológico, tanto no que tange à propaganda eleitoral como no que concerne aos demais aspectos passíveis de provocar uma alteração no normal desenvolvimento deste processo. Particularmente, deve ser proibida a propaganda subliminar e penalizada com todos os meios ao alcance do Estado de Direito.

Temos um caso recente na Espanha que serve como exemplo da importância de que os órgãos jurisdicionais tomem consciência dos problemas e da necessidade de oferecer uma resposta rápida e efetiva. Concretamente, a recente

25 “Decisions on whether to approve mergers, by the CMA and other authorities, have often focused on short-term impacts. In dynamic digital markets, long-run effects are key to whether a merger will harm competition and consumers. Could the company that is being bought grow into a competitor to the platform? Is the source of its value an innovation that, under alternative ownership, could make the market less concentrated? Is it being bought for access to consumer data that will make the platform harder to challenge? In principle, all of these questions can inform merger decisions within the current, mainstream framework for competition, centred on consumer welfare" (FURMAN, Jason et al. Unlocking digital competition. Report of the Digital Competition Expert Panel. Londres: Crown, 2019. p. 12. Disponível em: https://assets.publishing.service.gov.uk/government/uploads/system/uploads/attachment_data/ file/785547/unlocking_digital_competition_furman_review_web.pdf. Acesso em: 29 maio 2020). 
aprovação da Lei Orgânica no 3/2018, de 5 de dezembro, de proteção de dados pessoais e garantia dos direitos digitais, que em sua Disposição Adicional Terceira modificava a Lei Orgânica do Regime Eleitoral Geral, incorporando um art. 58 bis no qual se permitia aos partidos políticos reunir dados pessoais relativos a opiniões políticas das pessoas no contexto de suas atividades eleitorais "com as adequadas garantias". Os partidos poderiam utilizar dados pessoais obtidos em páginas web e outras fontes de acesso público para a realização de atividades políticas durante o período eleitoral. Esta reforma foi declarada inconstitucional tão só alguns meses depois, mediante a STC no 76/2019 de 22 de maio. A sentença baseia a declaração de inconstitucionalidade e nulidade no seguinte fato:

a Lei Orgânica 3/2018 não estabeleceu por si mesma, conforme imposto pelo art. 53.1 CE, as garantias adequadas no que tange especificamente à compilação de dados pessoais relativos às opiniões políticas pelos partidos políticos no contexto de suas atividades eleitorais. Isto constitui uma ingerência no direito fundamental à proteção de dados pessoais de gravidade similar à que causaria uma intromissão direta no seu conteúdo nuclear.

\subsection{Medidas fiscais}

As medidas fiscais constituem uma vertente fundamental da atuação contra as práticas danosas das companhias que gerenciam as redes sociais. Ao estarem, tais companhias, voltadas para a rentabilidade econômica, as medidas fiscais podem constituir um elemento compensatório que possibilite a utilização dos fundos obtidos para estabelecer instituições e mecanismos de controle assim como de educação digital da coletividade.

Tais medidas fiscais também podem representar o mecanismo que permita controlar os efeitos disfuncionais da atividade destas plataformas sobre os meios de comunicação tradicionais, caso estejam acompanhadas de benefícios fiscais que possibilitem a permanência e estabilidade de tais meios.

\subsection{Sanções}

As sanções econômicas são muito importantes para lutar contra as práticas danosas das companhias tecnológicas, precisamente porque afetam sua rentabilidade, que é a base de seu atual modelo de negócio. É recomendável que tais sanções se correspondam com a entidade que provoca os danos, podendo 
alcançar porcentagens de seu volume de negócio total anual global (conforme já previsto por legislações setoriais como a europeia relativa à proteção de dados).

As sanções penais são sempre o último recurso, porém seriam necessárias para práticas danosas produzidas em relação aos processos eleitorais, como é o caso da propaganda subliminar particularizada em função de perfis psicológicos previamente elaborados através de algoritmos. Este tipo de intervenção nos processos eleitorais não constitui uma questão menor e requer uma resposta muito firme do ordenamento jurídico para evitar uma desfiguração completa dos processos democráticos.

\section{Conclusões}

Na relação entre redes sociais e democracia é necessário considerar um mediador fundamental, que são as empresas tecnológicas que gerenciam as redes. Este mediador manteve-se oculto durante muito tempo, ao ponto de ter sido normal pensar nas redes como um instrumento de comunicação política sem mediadores (diferentemente dos meios de comunicação tradicionais), o que, evidentemente, não é o caso. As redes sociais não representam um fenômeno natural surgido nos processos sociais e políticos espontaneamente. São o resultado de opções empresariais que configuraram um modelo de negócio baseado em atrair a atenção do público para otimizar os ganhos publicitários mediante utilização contínua das redes. Este modelo de negócio está provocando importantes problemas nos processos de comunicação política porque fomenta a fragmentação do espaço público e sua radicalização com a finalidade de incrementar o uso de tais redes, obtendo, assim, maiores ganhos. A esta finalidade econômica se une a política, de gerar instabilidade para debilitar as instituições democráticas e dificultar, assim, o controle que tais instituições deveriam implementar sobre as próprias companhias tecnológicas.

São muitos os âmbitos nos quais as redes sociais têm gerado disfunções do ponto de vista constitucional e democrático. Desde os direitos fundamentais até os processos eleitorais, passando pela própria configuração da ordem constitucional, num contexto no qual as condições do espaço e do tempo foram transformadas em razão da globalização e do desenvolvimento tecnológico. Novas pautas culturais e novos paradigmas estão em surgimento e sua incidência sobre o constitucionalismo é muito ampla. Algumas das mudanças trazidas pelas redes sociais podem ser estruturais e manter-se-ão previsivelmente no futuro. Outras, no entanto, podem se considerar diretamente vinculadas aos interesses das companhias tecnológicas e deveriam ser objeto de revisão para evitar que levem 
a uma involução democrática. A intervenção dos poderes públicos, estatais e supranacionais, é cada vez mais necessária para controlar tais companhias.

As medidas que podem ser tomadas são muito diversas. Desde reforçar a proteção dos direitos fundamentais até promover a educação digital dos cidadãos, passando por intervenções destinadas a evitar que as companhias tecnológicas consolidem posições de monopólio, assim como medidas fiscais e sancionadoras etc. De particular importância é a regulação dos processos eleitorais para evitar que continuem se produzindo interferências através de notícias falsificadas e por meio da propaganda subliminar particularizada. O horizonte move-se em todo caso, à medida em que avança o desenvolvimento tecnológico e que estas companhias esboçam novas estratégias. Portanto, faz-se necessário levar em consideração que os riscos não são somente aqueles que hoje conhecemos, porém, que será necessário manter uma postura vigilante para evitar que se produzam novos efeitos disfuncionais no futuro.

\title{
Social networks, tech companies and democracy
}

\begin{abstract}
There are many areas in which social networks have generated dysfunctions from a constitutional and democratic point of view. From fundamental rights to electoral processes, through the very configuration of constitutional order, in a context in which the conditions of space and time have been transformed by globalization and technological development. New cultural guidelines and new paradigms are emerging and their impact on constitutionalism is very broad. Some of the changes brought about by social networks may be structural and will continue predictably in the future. Others, however, can be considered directly linked to the concerns of technology companies and should be reviewed to prevent them from leading to a regression in democracy. Intervention by public, state and supranational authorities is increasingly necessary to control such companies.
\end{abstract}

Contents: Introduction - $\mathbf{1}$ The context of globalization - $\mathbf{2}$ Transformation of cultural agendas and change of paradigm - $\mathbf{3}$ Constitution, democracy and social networks - 4 Internet and network companies. Problematic aspects - $\mathbf{5}$ The communicative processes and the construction of public space - $\mathbf{6}$ The electoral processes - $\mathbf{7}$ Possible areas of operation - Conclusions - References

Keywords: Social networks. Technology companies. Democracy. Constitution. Fundamental rights.

\section{Referências}

BALAGUER CALLEJÓN, Francisco. El Tratado de Lisboa en el Diván. Una reflexión sobre constitucionalidad, estatalidad y Unión Europea. Revista Española de Derecho Constitucional, Espanha, n. 83, maio/ago. 2008.

BALAGUER CALLEJÓN, Francisco. Las dos grandes crisis del constitucionalismo frente a la globalización en el siglo XXI. Nomos, Le attualità nel diritto, Roma, 2018. Disponível em: http://www.nomosleattualitaneldiritto.it/wp-content/uploads/2018/09/Callehon.-conv-11.05.pdf. Acesso em: 29 maio 2020. 
BONNET, Julien; TÜRK, Pauline. Le numérique: un défi pour le droit constitutionnel. Les Nouveaux Cahiers du Conseil constitutionnel, v. 57, n. 4, p. 13-24, 2017.

CARBONELL, Miguel; FIX-FIERRO, Héctor; GONZÁLEZ PÉREZ, Luis Raúl; VALADÉS, Diego (Coord.). Estado constitucional, derechos humanos, Justicia y vida universitaria. Estudios en homenaje a Jorge Carpizo. México: Unam, 2015. t. IV. v. 1.

DEB, Anamitra; DONOHUE, Stacy; GLAISYER, Tom. Is social media a threat to democracy? The Omidyar Group, 2017. Disponível em: https://www.omidyargroup.com/wp-content/uploads/2017/10/SocialMedia-and-Democracy-October-5-2017.pdf. Acesso em: 29 maio 2020.

FASSASSI, Idris. Les effets des réseaux sociaux dans les campagnes électorales américaines. Les Nouveaux Cahiers du Conseil constitutionnel, v. 57, n. 4, p. 69-86, 2017.

FROSINI, Tommaso Edoardo. Internet e democrazia. /l diritto dell'informazione e dell'informatica, anno XXXII, fasc. 4-5, p. 657-671, 2017.

FURMAN, Jason et al. Unlocking digital competition. Report of the Digital Competition Expert Panel. Londres: Crown, 2019. Disponível em: https://assets.publishing.service.gov.uk/government/uploads/ system/uploads/attachment_data/file/785547/unlocking_digital_competition_furman_review_web.pdf. Acesso em: 29 maio 2020.

INGLATERRA. House of Commons. Digital, Culture, Media and Sport Committee, DCMS. Disinformation and 'fake news': Final Report. Londres: House of Commons, 2019. Disponivel em: https://publications. parliament.uk/pa/cm201719/cmselect/cmcumeds/1791/1791.pdf. Acesso em: 29 maio 2020.

MARK, Scott. Cambridge Analytica helped 'cheat' Brexit vote and US election. Politico, 29 mar. 2018. Disponivel em: https://www.politico.eu/article/cambridge-analytica-chris-wylie-brexit-trump-britain-dataprotection-privacy-facebook/. Acesso em: 29 maio 2020.

NIALL, Ferguson. Social networks are creating a global crisis of democracy. The Globe and Mail, 2018. Disponivel em: https://www.theglobeandmail.com/opinion/niall-ferguson-social-networks-and-the-globalcrisis-of-democracy/article37665172/. Acesso em: 29 maio 2020.

PAPA, Anna. I/ diritto ad essere informati nella tutela multilivello della libertà di espressione. No prelo. PARISER, Eli. The Filter Bubble. What the internet is hiding from you. Londres: Penguin Books, 2011.

PITRUZZELLA, Giuseppe. La libertà di informazione nell'era di Internet. In: PITRUZZELA, Giovanni; POLLICINO, Oreste; QUINTARELLI, Stefano. Parole e potere: libertà d'espressione, hate speech e fake news. Milão: Egea, 2017.

RICHAUD, Coralie. Les réseaux sociaux: nouveaux espaces de contestation et de reconstruction de la politique? Les Nouveaux Cahiers du Conseil constitutionnel, v. 57, n. 4, p. 29-44, 2017.

ROUSSEAU, Dominique. 1948-2018: que reste-t-il de la Déclaration universelle des droits de l'homme? Libération, 6 dez. 2018. Disponivel em: https://www.liberation.fr/auteur/8617-dominique-rousseau. Acesso em: 29 maio 2020.

ROUSSEAU, Dominique. Le numérique, nouvel objet du droit constitutionnel. Les Nouveaux Cahiers du Conseil constitutionnel, v. 57, n. 4, 2017.

SALES, Eric. La transformation de l'écriture de la Constitution, l'exemple islandais. Les Nouveaux Cahiers du Conseil constitutionnel, v. 57, n. 4, p. 45-57, 2017.

THE CAIRNCROSS REVIEW. A sustainable future for journalism. 12 February 2019. Disponível em: https://assets.publishing.service.gov.uk/government/uploads/system/uploads/attachment_data/ file/779882/021919_DCMS_Cairncross_Review_.pdf. Acesso em: 29 maio 2020. 
VIDAL-NAQUET, Ariane. La transformation de l'écriture de la loi: I'exemple de la loi sur la République numérique. Les Nouveaux Cahiers du Conseil constitutionnel, v. 57, n. 4, p. 59-68, 2017.

Informação bibliográfica deste texto, conforme a NBR 6023:2018 da Associação Brasileira de Normas Técnicas (ABNT):

BALAGUER CALLEJÓN, Francisco. Redes sociais, companhias tecnológicas e democracia. Direitos Fundamentais \& Justiça, Belo Horizonte, ano 14, n. 42, p. 25-48, jan./jun. 2020.

Recebido em: 14.11.2019

Aprovado em: 25.05.2020

Cota Convite 